\title{
Supramolecular Gel-Assisted Synthesis of Double Shelled Co@CoO@N-C/C Nanoparticles with Synergistic Electrocatalytic Activity for the Oxygen Reduction Reaction
}

\begin{abstract}
Zexing Wu, ${ }^{a}$ Jie Wang, ${ }^{a}$ Lili Han, ${ }^{\text {bcc }}$ Ruoqian Lin, ${ }^{b, d}$ Hongfang Liu, ${ }^{a}$ Huolin L. Xin,,${ }^{b, d}$ and Deli $\mathrm{Wang}^{a}$,*

Investigating active, stable, and low-cost materials for the oxygen reduction reaction is one of the key challenges in fuel-cell research. In this work, we describe the formation of N-doped carbon shell coated Co@CoO nanoparticles supported on Vulcan XC-72 carbon materials (Co@CoO@N-C/C) based on a simple supramolecular gel-assisted method. The double-shelled Co@CoO@N-C/C core-shell nanoparticles exhibit superior electrocatalytic activities for the oxygen reduction reaction than that of $\mathrm{N}$-doped carbon and cobalt oxide, demonstrating the synergistic effect of the hybrid nanomaterials. Notably, the Co@CoO@N-C/C nanoparticles give rise to a comparable four-electron selectivity, long-term stability, and high methanol tolerance; all are multi-fold improved upon the commercial Pt/C catalyst. The progress is of great importance in exploring advanced non-precious metal-based electrocatalysts for fuel cells applications.
\end{abstract}

\section{Introduction}

Developing catalytic materials with high efficiency and low cost for the oxygen reduction reaction (ORR) at the cathode is one of the technological bottlenecks for fuel cells and metal-air

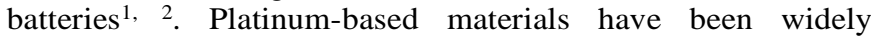
recognized as the best catalysts to overcome the sluggish reaction kinetics of the $\mathrm{ORR}^{3}$. However, the high cost and scarcity of platinum, as well as its susceptibility to be poisoned by organic molecular and poor long-term stability have limited the large-scale production and commercialization of the fuel cells $^{4}$. Therefore, it is of great importance to develop new materials to replace Pt-based catalysts ${ }^{5-7}$. Great efforts have been devoted to exploring non-precious metal or 3d-transition metal/metal oxide catalysts ${ }^{8,9}$ or heteroatoms (e.g. N, S, P, B) doped carbon materials ${ }^{10}$. Moreover, the combination of nonprecious metal and heteroatoms doped carbon could further enhance the ORR performance ${ }^{11-13}$

Cobalt phthalocyanine is the first reported non-precious metal catalyst in alkaline conditions for the ORR ${ }^{14}$. However, the activity deteriorates significantly over time. Even though the activity and stability could be improved through thermally treatment ${ }^{15}$, the catalytic performance is still much worse than that of commercial $\mathrm{Pt} / \mathrm{C}$. On the other hand, the non-precious metal macrocycle composites are expensive for their special structure. Recently, the expensive macrocycle composites are replaced by the complexes of nitrogen precursors (e.g. polyacrylonitrile $(\mathrm{PAN})^{16}$, polypyrrole $(\mathrm{PPy})^{17}$ ) and metal salts. However, the role of metal in the electrocatalysts remains unclear. Wang et al. postulated that metal did not participate in the electrocatalytical reaction but facilitated the formation of

a. Key laboratory of Material Chemistry for Energy Conversion and Storage (Huazhong University of Science and Technology), Ministry of Education, Hubei Key Laboratory of Material Chemistry and Service Failure, School of Chemistry and Chemical Engineering, Huazhong University of Science and Technology E-mail: wangdl81125@hust.edu.cn

b. Center for Functional Nanomaterials, Brookhaven National Laboratory, Upton, $N Y, U S A$

School of Materials Science and Engineering, Tianjin University, Tianjin 300072, P.R. China

d. Department of Materials Science and Engineering, Stony Brook University, Stony Brook, NY, 11794, USA

$\doteqdot$ Electronic Supplementary Information (ESI) available. Se DOI: $10.1039 / \mathrm{x} 0 \mathrm{xx} 00000 \mathrm{x}$ active sites ${ }^{18}$. On the contrary, $\mathrm{Hu}$ et $\mathrm{al}^{19}$ and Liu et $\mathrm{al}^{20}$ claimed that the trace amount of metal significantly promote the ORR performance. Herein, we develop a supramolecular gel-assisted strategy to prepare $\mathrm{N}$-doped carbon shell coated $\mathrm{Co} / \mathrm{CoO}$ nanoparticles supported on Vulcan XC-72 carbon materials (Co@CoO@N-C/C) as efficient non-Pt catalyst for the ORR. The resulting hybrid materials not only exhibit excellent electrocatalytic activities compared with carbon materials and cobalt oxides but also exhibit long-term stability and methanol tolerance in contrast to the poor performance of commercial Pt$\mathrm{C}$ electrocatalyst in this regard. This strategy shed light on exploring highly active and stable non-precious metal electrocatalysts for fuel cells application.

Supramolecular hydrogel, a sub-solid substance, is formed by non-covalent interactions such as hydrogen bonds, $\pi-\pi$ interactions, van der Waals forces, hydrophobic interactions etc. ${ }^{21}$ Until now, there are few reports on the application of the gel method in energy conversion. For examples, Wohlgemuth et al. synthesized $\mathrm{S}$ and $\mathrm{N}$ co-doped carbon aerogel via one pot hydrothermal method to enhance the electrocatalytic activity for the $\mathrm{ORR}^{22}$. Jin et al. reported $\mathrm{N}$-doped xerogel through solgel polymerization method followed by a pyrolysis process which was used as catalysts for fuel cells ${ }^{23}$. Seredch et al. indicated that graphite oxides were thermally reduced within confined space of commercial silica gel, resulting in highly catalytic activities for both ORR and oxygen evolution reaction (OER) in neutral electrolyte ${ }^{24}$. Nevertheless, the preparation and post-treatment of the gel is a complicate process, it is tedious and time-consuming. In this study, as illustrated in Scheme 1, melamine possess nine $\mathrm{H}$-bonding sites among which the $\mathrm{sp}^{2}$ hybridized nitrogen atoms on the triazine ring of each monomer provides three unpaired electrons, which acts as $\mathrm{H}$-bonding acceptor and the six additional H-bond could be shared with other functional groups, so hydrogen bond and electrostatic interactions took place when nitric acid mixed with melamine to form low molecular weight hydrogel ${ }^{25}$. At the same time, melamine acts as nitrogen source for heteroatom doping ${ }^{26}$ during the pyrolysis, but the high content of nitrogen can decrease the carbonization yield. Vulcan XC-72, a commonly used carbon support for catalytic materials were uniformly dispersed in the solution before the formation of supramolecular hydrogel (Fig. S1, Supporting Information). In this way, melamine and Vulcan compact together tightly and facilitate the nitrogen doping. Moreover, the weak interaction 
between $\mathrm{Co}^{2+}$ and melamine decrease the aggregation of $\mathrm{Co}$ nanoparticles ${ }^{27}$.

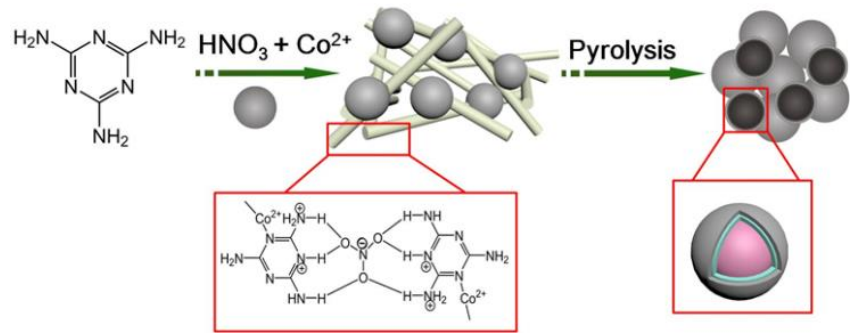

Scheme 1 Schematic illustration for the synthesis of Co@CoO@N-C/C.

\section{Experimental}

Sample preparation. As illustrated in scheme $1,0.5 \mathrm{~mL}$ of concentrated nitric acid (Sinopharm Chemical Reagent Co. Ltd. China) mixed with $19.5 \mathrm{~mL}$ deionized water in a $50 \mathrm{~mL}$ beaker and $0.7 \mathrm{~g}$ of melamine (Sinopharm Chemical Reagent Co. Ltd. China) were added, and heated until a transparent solution formed. Then, Vulcan XC-72 $(0.35 \mathrm{~g}$, pretreated with concentrated $\mathrm{HNO}_{3}$ at $110{ }^{\circ} \mathrm{C}$ for $3 \mathrm{~h}$ before was used in order to remove the metal impurities and enhance the wettability, Cabot Corporation, America) and $0.47 \mathrm{~g}$ of cobalt (II) nitrate hexahydrate (Aladdin Ltd. Shanghai, China) were added into the mixture and stirred until Vulcan $\mathrm{XC}-72$ was uniformly dispersed in this solution. Gel formed along with the mixture gradually cooling and dried at $60{ }^{\circ} \mathrm{C}$ overnight. Nitrogen doped electrocatalysts and melamine supported cobalt were prepared using the same method. Carbon supported cobalt was prepared by impregnation method for comparison. The precursors were heated to $600{ }^{\circ} \mathrm{C}, 700{ }^{\circ} \mathrm{C}$ and $800{ }^{\circ} \mathrm{C}$ at an increasing rate of $10{ }^{\circ} \mathrm{C} \min ^{-1}$ under $\mathrm{N}_{2}$ atmosphere. After maintaining 2 hours at different temperature, the samples were cooled to room temperature under $\mathrm{N}_{2}$ atmosphere which were designated as $\mathrm{Co} @ \mathrm{CoO} @ \mathrm{~N}-\mathrm{C} / \mathrm{C}, \mathrm{Co} / \mathrm{CoO} / \mathrm{C}, \quad \mathrm{M}-\mathrm{Co} / \mathrm{CoO}$ and $\mathrm{N}-\mathrm{C}$, respectively.

Physical characterization. The morphologies were examined by scanning electron microscopy (SEM, Sirion200). Transmission electron microscopy (TEM) images was conducted by a JSM2100 transmission electron microscopy (JEOL,Japan) at an acceleration voltage of $200 \mathrm{kV}$. Electron Energy Loss Spectroscopy (EELS) data were acquired using a Gatan Tridiem spectrometer. Powder X-ray diffraction (XRD) was performed by using an X'Pert PRO diffractometer, and diffraction patterns were collected at a scanning rate of $4^{\circ} \mathrm{min}^{-1}$. X-ray photoelectron spectroscopy (XPS) data were obtained using an AXIS-ULTRA DLD-600W Instrument. Thermal gravimetric analysis (TGA) was conducted on TA Q500 Instrument under flowing air at a heating rate of $10{ }^{\circ} \mathrm{C} / \mathrm{min}$.

Electrochemical measurements. All the electrochemical measurements were carried out using a three electrode system (GCE or modified GCE as working electrode, a Pt wire as a counter electrode and a reverse hydrogen electrode as a reference electrode) in $0.1 \mathrm{M} \mathrm{KOH}$ (Aladdin Ltd. Shanghai, China) aqueous solution at room temperature $(298 \mathrm{~K})$ with electrochemical workstation $\mathrm{CHI} 760 \mathrm{e}$ and high speed rotators from Pine Instrument. $5 \mathrm{mg}$ of samples was dispersed in $1 \mathrm{~mL}$ Nafion (Aladdin Ltd. Shanghai, China) solution (diluted with isopropyl alcohol) and sonicated to form a homogeneous ink $16.5 \mathrm{uL}$ of catalyst ink was dropped onto a GCE and allowed to dry in air naturally. The loading quantity of commercial $\mathrm{Pt} / \mathrm{C}$ (Aladdin Ltd. Shanghai, China) is about $15 \mu \mathrm{g} \mathrm{cm}{ }^{-2}$. Oxygen saturated electrolyte was performed by purging $\mathrm{O}_{2}$ and a flow of $\mathrm{O}_{2}$ was maintained during electrochemical measurement. Cyclic voltammograms (CV) was performed in $\mathrm{N}_{2-}$ or $\mathrm{O}_{2-}$ saturated $0.1 \mathrm{M} \mathrm{KOH}$ aqueous solution. For the rotating disk electrode (RDE) measurements, the working electrode was scanned at a rate of $5 \mathrm{mVs}^{-1}$ at various rotation speeds $(400$, $600,900,1200,1600$ and $2000 \mathrm{rpm})$. The kinetic current density and electron numbers (n) for the ORR derived from Koutecky-Levich plots:

$\frac{1}{j}=\frac{1}{j_{K}}+\frac{1}{j_{D}}$

$j_{D}=0.62 n F A D^{2 / 3} v^{-1 / 6} w^{1 / 2} C o_{2}$

where $j, j_{k}$ and $j_{D}$ corresponds to the measured, kinetic and diffusion limiting current, respectively, $\mathrm{n}$ is the electron number transferred, $\mathrm{F}$ is the Faraday constant $\left(96485 \mathrm{C} \mathrm{mol}^{-1}\right)$, A is the geometric electrode area $\left(0.196 \mathrm{~cm}^{2}\right), \mathrm{D}$ is the diffusion coefficient of oxygen, $\mathrm{v}$ is the kinetic viscosity of electrolyte, $\mathrm{w}$ is the rotating speed of $\mathrm{RDE}$ and $\mathrm{CO}_{2}$ is the saturated oxygen concentration in $0.1 \mathrm{M} \mathrm{KOH}$ solution. The mass activity at certain potential was obtained by dividing the kinetic current to mass of the catalysts. For the Tafel plot, the kinetic current density was calculated from the mass-transport correction of RDE based on the following equation:

$\boldsymbol{j}_{\boldsymbol{k}}=\frac{\boldsymbol{j} * \boldsymbol{j}_{\boldsymbol{D}}}{\boldsymbol{j}_{\boldsymbol{D}}-\boldsymbol{j}}$

The rotating ring-disk electrodes (RRDE) were conducted in $\mathrm{O}_{2}$-saturated $0.1 \mathrm{M} \mathrm{KOH}$ solution at the rotation rate of 1600 $\mathrm{rpm}$. The formation yields of peroxide $\left(\mathrm{H}_{2} \mathrm{O}_{2} \%\right)$ species with respect to the total ORR products and the electron reduction number $(\mathrm{n})$ calculated from RRDE via the following equations: $n=\frac{4 j_{D}}{j_{D}+\frac{j_{R}}{N}}$

$$
H_{2} \mathrm{O}_{2} \%=\frac{\frac{2 j_{R}}{N}}{j_{D}+\frac{j_{R}}{N}} \times 100 \%
$$

$j_{D}$ and $j_{R}$ denote the faradic current at the disk and ring electrode, respectively, and $\mathrm{N}$, collection efficiency, is taken as 0.37 for our experiment.

Linear sweep voltammetry (LSV) was measured in $\mathrm{O}_{2}$-saturated $\mathrm{KOH}$ aqueous at a scan rate of $5 \mathrm{mVs}^{-1}$ with rotating speed of 1600 $\mathrm{rpm}, \mathrm{CV}$ curves with a sweeping rate of $50 \mathrm{mV} \mathrm{s}^{-1}$ and i-t chronoamperometric response were conducted in $\mathrm{O}_{2}$-saturated $\mathrm{KOH}$ aqueous with $1 \mathrm{M}$ methanol to measure the methanol tolerance. The stability testing was carried out at a constant potential of $0.7 \mathrm{~V}$ for 20000 seconds with a rotating speed of $1600 \mathrm{rpm}$, and running 48 hours in $\mathrm{O}_{2}$ saturated $\mathrm{KOH}$ aqueous solution.

\section{Results and discussion}

The morphology of the pure melamine supramolecular gel is fibers interweaved as shown in Fig. 1a. The diameter of the melamine fiber grew shorter (Fig. 1b) with the addition of Vulcan XC-72 (carbon nanospheres with diameter of 30-50 nm, see Supporting Information Fig. S2), indicating the restriction of carbon for the forming of the fiber. It is reported that the morphology of the supramolecular is easily affected by the environment, such as solution ${ }^{28}$, ion ${ }^{29}$ and preparation $\operatorname{method}^{30}$. During the pyrolysis of supramolecular gel, 
melamine serves as nitrogen and carbon sources, forming a $\mathrm{N}$ doped carbon shell coated Co nanoparticles supported on Vulcan XC-72 carbon (Fig. 1c). Transmission electron microscopy (TEM) images clearly show that the Co nanoparticles completely coated with carbon shells (Fig. 1d). However, cobalt nanoparticles without carbon shell (Fig. S3a) can be clearly seen in the $\mathrm{Co} / \mathrm{CoO} / \mathrm{C}$ catalyst, moreover, the cobalt aggregated seriously without Vulcan in $\mathrm{M}-\mathrm{Co} / \mathrm{CoO}$ (Fig. S3b). It demonstrated that Vulcan plays an important role in avoiding the cobalt aggregation and besides, the carbon shell on Co@CoO@N$\mathrm{C} / \mathrm{C}$ is derived from melamine rather than Vulcan. Thermo gravimetric Analysis (TGA) shows an obvious weight increase at $350{ }^{\circ} \mathrm{C}$ and a sharp decrease of relative weight percent after $350{ }^{\circ} \mathrm{C}$ which illustrated the oxidation of cobalt and carbon (derived from the carbonization of melamine) (Fig. S4), respectively. Therefore, both Vulcan and melamine are indispensable to form double shelled structure which exhibits excellent ORR performance and outstanding stability. The d-spacing of $0.204 \mathrm{~nm}$ corresponds

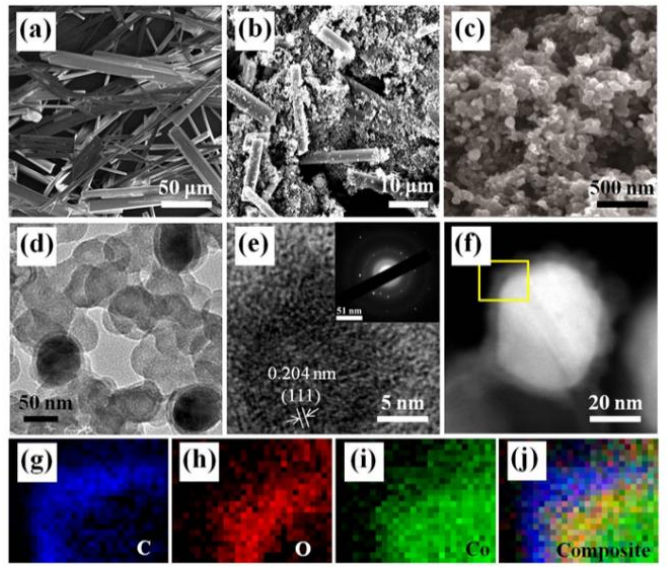

Fig. 1 FE-SEM images of pure melamine supramolecular gel (a), mixed melamine supramolecular gel (b), heat-treatment sample (c). (d) TEM image of the hybrid. (e) High resolution TEM image of the nanoparticle (The inset is the selected area electron diffraction (SAED) patterens). (f) STEM image of one Co@CoO@N-C/C core-shell nanoparticle. EELS elemental mapping of $\mathrm{C}(\mathrm{g}), \mathrm{O}(\mathrm{h}), \mathrm{Co}(\mathrm{i})$ and overlay of $\mathrm{C}, \mathrm{O}$ and $\mathrm{Co}(\mathrm{j})$.

to the (111) plane of Co (Fig. 1e). The selected area electron diffraction (SAED) patterns further confirm that the Co nanoparticles have a good crystalline structure. Cobalt and other transition metals have been reported previously for mediating the formation of carbons structures, such as $\mathrm{CNT}^{31}$ ${ }^{32}$, graphene layers, etc ${ }^{33}$. The carbon shell prevents the electrolyte to contact the metal directly and aggregation of the metal particles, improving the stability of the catalysts ${ }^{34,35}$. The carbon shell is likely derived from melamine since there are weak interaction exist between $\mathrm{Co}^{2+}$ and melamine as shown in the Fourier Transform Infrared Spectrometer (FT-IR) (Fig. S5, Supporting Information). The vibration frequencies for semicircle and quadrant stretching of the triazine ring increased from $1435.75 \mathrm{~cm}^{-1}$ to $1437.85 \mathrm{~cm}^{-1}$ and $1545.09 \mathrm{~cm}^{-1}$ to $1552.35 \mathrm{~cm}^{-1}$ attributed to the coordination of $\mathrm{Co}^{2+}$ to ring nitrogen $^{36,37}$. The elemental composition analysis in Fig. 1 (g-j) and the line profile in Fig. S6 clearly show the carbon shell coated on the $\mathrm{Co} @ \mathrm{CoO}$ nanoparticle. The doped $\mathrm{N}$ in the carbon shell is barely detectable probably because of its content in the carbon shell is below the detection limit. However, we can clearly see that N1s at $\sim 400 \mathrm{eV}$ from XPS survey spectrum in Fig. 2a, indicating the doping of $\mathrm{N}$ in the carbon support and carbon shell. Besides, there is a predominant $\mathrm{C} 1$ s peak at $\sim 284$
$\mathrm{eV}$ and a weak Co $2 \mathrm{p}$ peak at $\sim 781 \mathrm{eV}$ in the XPS survey spectrum of $\mathrm{Co} @ \mathrm{CoO} @ \mathrm{~N}-\mathrm{C} / \mathrm{C}$. However, there are no peaks of $\mathrm{Co}$ in $\mathrm{N}-\mathrm{C}$ and $\mathrm{N}$ in $\mathrm{Co} / \mathrm{CoO} / \mathrm{C}$ (Fig. S7), respectively, indicating that $\mathrm{Co}$ and $\mathrm{N}$ atoms doped into $\mathrm{Co} @ \mathrm{CoO} @ \mathrm{~N}-\mathrm{C} / \mathrm{C}$ nanoparticles ${ }^{38}$ and $\mathrm{N}$ comes from melamine not the anion of $\mathrm{NO}_{3}{ }^{-}$. Furthermore, the content of $\mathrm{N}$ in $\mathrm{N}-\mathrm{C}(0.99 \%)$ is lower than in $\mathrm{Co} @ \mathrm{CoO} @ \mathrm{~N}-\mathrm{C} / \mathrm{C}(1.93 \%)$, indicating the existence of Co is benefit for nitrogen doping.

The high resolution XPS spectrum of N1s shown in Fig. 2b could be deconvoluted into three peaks, corresponding to graphitic $\mathrm{N}(400.3 \mathrm{eV})$, pyrrolic $\mathrm{N}(398.9 \mathrm{eV})$ and pyridinic $\mathrm{N}$ $(397.9 \mathrm{eV})$, respectively ${ }^{39}, 40$. In the Co $2 \mathrm{p}_{3 / 2}$ spectrum for Co@CoO@N-C/C in Fig. 2c, two kinds of Co species with a satellite peak were detected. The binding energy at $779.5 \mathrm{eV}$ is ascribed to metallic cobalt (0). The peak at $781 \mathrm{eV}$ is the typical characteristic of $\mathrm{Co}^{2+}$ on the octahedral for rocksalt $\mathrm{CoO}$, which is in accordance with previously reported data ${ }^{41,42}$
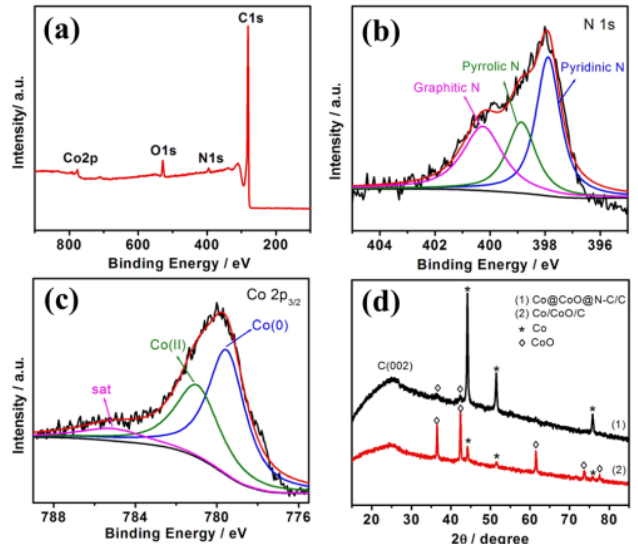

Fig. 2 (a) Survey XPS spectrum of the CoO@Co@N-C/C nanoparticle. High-resolution XPS spectra of N1s (b) and Co2p (c). (d) Powder XRD patterns of $\mathrm{Co@CoO@N-C/C} \mathrm{and}$ $\mathrm{Co} / \mathrm{CoO} / \mathrm{C}$.

Fig. 2d and Fig. S8 show the XRD patterns of Co@CoO@N$\mathrm{C} / \mathrm{C}, \mathrm{Co} / \mathrm{CoO} / \mathrm{C}$ and $\mathrm{M}-\mathrm{Co} / \mathrm{CoO}$ catalysts. For $\mathrm{Co} @ \mathrm{CoO} @ \mathrm{~N}-\mathrm{C} / \mathrm{C}$ nanoparticles, the diffraction peaks at $44.2^{\circ}, 51.5^{\circ}, 75.8^{\circ}$ corresponds to (111), (200), (220) crystal facets of metallic Co with a face-centered cubic (fcc) crystalline structure (JCPDS NO. 89-4307). Besides, there are two weak peaks located at $36.5^{\circ}, 42.4^{\circ}$ attributes to $\mathrm{CoO}$, in accordance with the EELS elemental mapping and XPS data. The presence of metallic Co revealed that $\mathrm{Co}^{2+}$ was reduced to metallic Co during the pyrolysis process ${ }^{38}$. The existence of $\mathrm{CoO}$ is likely arose from the oxidization of Co when the sample exposed to air ${ }^{43,44}$. However, the carbon shell prevents the oxidation of $\mathrm{CoO}$ to large crystal. Unlike the $\mathrm{Co} / \mathrm{CoO} / \mathrm{C}$ and $\mathrm{M}-\mathrm{Co} / \mathrm{CoO}$, two types of peaks corresponding to metallic $\mathrm{Co}$ and $\mathrm{CoO}$, respectively. But the diffraction peaks of metallic $\mathrm{Co}$ in $\mathrm{Co} / \mathrm{CoO} / \mathrm{C}$ is much weaker than in $\mathrm{Co} @ \mathrm{CoO} @ \mathrm{~N}-\mathrm{C} / \mathrm{C}$ and $\mathrm{M}-\mathrm{Co} / \mathrm{CoO}$, which indicates that melamine derived carbon shell plays an important role to protect metallic Co oxidized seriously.

The ORR electrocatalytic activities of the materials were first investigated by cyclic voltammetry (CV) measurement. As shown in Fig. 3a, a featureless capacitive current was shown for all the samples in $\mathrm{N}_{2}$-saturated $0.1 \mathrm{M} \mathrm{KOH}$ solution, while obvious oxygen reduction peaks were observed in $\mathrm{O}_{2}$-saturated solution, indicating the catalytic reduction of oxygen on the different electrodes. Remarkably, the Co@CoO@N-C/C electrode shows a distinct ORR peak at $0.79 \mathrm{~V}$, which is over $80 \mathrm{mV}$ and $40 \mathrm{mV}$ more positive than on $\mathrm{C}-\mathrm{N}$ and $\mathrm{Co} / \mathrm{CoO} / \mathrm{C}$, indicating that oxygen can be reduced much more easily on Co@CoO@N-C/C. The enhanced catalytic activity on 
Co@CoO@N-C/C is attributed to the synergistic catalytic effect of cobalt and $\mathrm{N}$-doped carbon for ORR in the nanocomposites that probably caused by the electronic interaction between Co core and $\mathrm{N}$-doped carbon shell, which was verified by XPS spectra. As shown in Fig. S9, the binding energy of N 1s peak on Co@CoO@N-C/C shifts to higher direction compared with $\mathrm{N}-\mathrm{C}$, while Co $2 \mathrm{p}$ moves to lower binding energy, revealing the electronic interaction between Co and $\mathrm{N}^{45,46}$ which is responsible for the synergistic enhancement of ORR catalytic activity. To further insight into the ORR process of the materials, rotating-disk electrode (RDE) measurements were performed. The ORR polarization curves in Fig. 3b revealed that $\mathrm{Co} @ \mathrm{CoO} @ \mathrm{~N}-\mathrm{C} / \mathrm{C}$ electrode exhibits much better ORR performance (onset potential at $0.92 \mathrm{~V}$, halfwave potential at $0.81 \mathrm{~V} v s$. RHE) compared with Vulcan XC72 (Fig. S10, onset potential at $0.76 \mathrm{~V}$, half-wave potential at $0.66 \mathrm{~V} v s . \mathrm{RHE}$ ), C-N (onset potential at $0.83 \mathrm{~V}$, half-wave potential at $0.72 \mathrm{~V} v s . \mathrm{RHE}$ ), $\mathrm{Co} / \mathrm{CoO} / \mathrm{C}$ (onset potential at 0.84 $\mathrm{V}$, half-wave potential at $0.76 \mathrm{~V} v s$. RHE), M-Co/CoO (Fig. S11) and a comparable activity to $\mathrm{Pt} / \mathrm{C}$ (onset potential at $0.95 \mathrm{~V}$, half-wave potential at $0.83 \mathrm{~V} v s$. RHE). The material obtained after heat-treated at $700{ }^{\circ} \mathrm{C}$ exhibited slightly higher ORR activity than $600{ }^{\circ} \mathrm{C}$ and $800{ }^{\circ} \mathrm{C}$ as shown in Fig. S12(a) and possessed excellent ORR performance compared with the reported Co based related catalysts (Table S1). The ORR performance of samples prepared by adding different mass of melamine was shown in Fig. S12(b) in order to investigate the mass effects of melamine on the electrochemical performance. Due to the difficulty of melamine dissolution in water, the ORR performance increased not obviously when melamine added in our experiment, on contrary, the electrocatalytic performance decreased in some extent when the mass of melamine reduced. The excellent performance could be attributed to the closely stacking between melamine and carbon, facilitating the decoration of nitrogen in carbon materials during pyrolysis, which is beneficial for the ORR activity enhancement ${ }^{47}$. Furthermore, the weak interaction between $\mathrm{Co}^{2+}$ and melamine could prevent the metal aggregation and then improving the contact opportunity between electrocatalyst and oxygen ${ }^{27}$.

To reveal the ORR kinetics of Co@CoO@N-C/C systematic polarization measurements were carried out at a scanning rate of $5 \mathrm{mV} \mathrm{s}^{-1}$ with different rotation rates (Fig. 3c). The limiting diffusion current density increased with increasing rotation speed, indicating that the current was kinetically controlled $^{48}$. The Koutecky-Levich plots $\left(j^{-1}\right.$ vs. $\left.\omega^{-1 / 2}\right)$ at the potentials of $0.6,0.65,0.7$ and $0.75 \mathrm{~V}$ show the linearity and parallelism (Fig. 3d), indicating the similar electron transfer numbers for ORR at different potentials. The electron numbers were calculated to be around 4 from the slop of KouteckyLevich plots (Fig. 3d and equation (1), (2) in the experimental section), indicating the hybrid nanocomposite follows the fourelectron reduction pathway. The paralleled lines indicate the first order reaction kinetics for ORR with respect to the concentration of dissolved oxygen ${ }^{49}$ and the electron transfer numbers for ORR at different potentials are similar which was calculated to be $4^{50}$, followed the four-electron transfer pathway, which is similar to commercial $\mathrm{Pt} / \mathrm{C}$ catalyst. Moreover, Tafel plot (Fig. S13) was also provided to reveal the ORR mechanism which was derived from the mass-transport correction of $\mathrm{RDE}$ data based on equation (3), $\mathrm{Co} @ \mathrm{CoO} @ \mathrm{~N}-\mathrm{C} / \mathrm{C}$ and $\mathrm{Co} / \mathrm{CoO} / \mathrm{C}$ have similar Tafel slopes with $\mathrm{Pt} / \mathrm{C}$, so they undergo the similar ORR mechanism: the protonation of $\mathrm{O}_{2}{ }^{-}$on the active sites of catalyst is the main rate-determining step. $\mathrm{Co} @ \mathrm{CoO} @ \mathrm{~N}-\mathrm{C} / \mathrm{C}$ exhibits the highest kinetic current at a given potential except $\mathrm{Pt} / \mathrm{C}$. It is further demonstrated that the $\mathrm{Co} @ \mathrm{CoO} @ \mathrm{~N}-\mathrm{C} / \mathrm{C}$ possess the best catalytic performance. At $0.8 \mathrm{~V}$, the mass activities (MA) based on Co are $29.7 \mathrm{mAmg}^{-1}, 15.8 \mathrm{mAmg}^{-1}$, and the values are $12.83 \mathrm{mAmg}^{-1}, 3.09$
$\mathrm{mAmg}^{-1}$ at $0.85 \mathrm{~V}$ on $\mathrm{Co} @ \mathrm{CoO} @ \mathrm{~N}-\mathrm{C} / \mathrm{C}$ and $\mathrm{Co} / \mathrm{CoO} / \mathrm{C}$, respectively (Fig. 3e). If the activities were calculated based on total materials on the electrode, the MA of $\mathrm{Co@CoO@N-C/C} \mathrm{were} 4.85$ $\mathrm{mAmg}^{-1}$, and $2.18 \mathrm{mAmg}^{-1}$, at $0.8 \mathrm{~V}$ and $0.85 \mathrm{~V}$, respectively. While for $\mathrm{Co} / \mathrm{CoO} / \mathrm{C}$, the MA valuses were $2.83 \mathrm{mAmg}^{-1}$ and $0.58 \mathrm{mAmg}^{-1}$ at $0.8 \mathrm{~V}$ and $0.85 \mathrm{~V}$, respectively (Fig. 3f). The MA of $\mathrm{Co} @ \mathrm{CoO} @ \mathrm{~N}$ $\mathrm{C} / \mathrm{C}$ is much higher than that of $\mathrm{Co} / \mathrm{CoO} / \mathrm{C}$, no matter what the activities were calculated based on cobalt or total materials on the electrode.
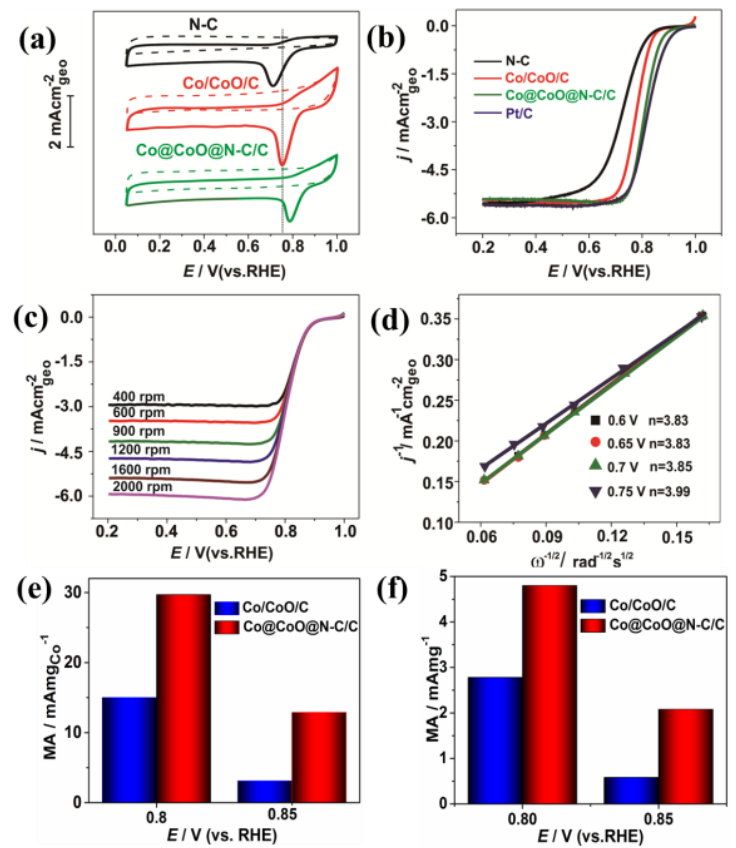

Fig. 3 (a) CV curves of N-C, $\mathrm{Co} / \mathrm{CoO} / \mathrm{C}$ and $\mathrm{Co} @ \mathrm{CoO} @ \mathrm{~N}-\mathrm{C} / \mathrm{C}$ in $\mathrm{O}_{2}$ - and $\mathrm{N}_{2}$-saturated $0.1 \mathrm{M} \mathrm{KOH}$ electrolyte at a scan rate of $50 \mathrm{mV} \mathrm{s}^{-1}$. (b) ORR polarization curves of $\mathrm{N}-\mathrm{C}, \mathrm{Co} / \mathrm{CoO} / \mathrm{C}$ and Co@CoO@N-C/C in $\mathrm{O}_{2}$-saturated $0.1 \mathrm{M} \mathrm{KOH}$ electrolyte at a scanning rate of $5 \mathrm{mV} \mathrm{s}^{-1}$ with a rotation rate of $1600 \mathrm{rpm}$. (c) ORR polarization curves of $\mathrm{Co} @ \mathrm{CoO} @ \mathrm{~N}-\mathrm{C} / \mathrm{C}$ in $\mathrm{O}_{2}$-saturated $0.1 \mathrm{M} \mathrm{KOH}$ solution at different rotation rates. (d) KouteckyLevich plots at potentials of $0.6,0.65,0.7$ and $0.75 \mathrm{~V}$. (e), (f) Comparison of mass activity (MA) for $\mathrm{Co} / \mathrm{CoO} / \mathrm{C}$ and $\mathrm{Co} @ \mathrm{CoO} @ \mathrm{~N}-\mathrm{C} / \mathrm{C}$ at 0.8 and $0.85 \mathrm{~V}$ based on the mass of cobalt and total materials on the electrode.

To further insight into the kinetics and the catalytic pathways of the ORR on $\mathrm{Co} @ \mathrm{CoO} @ \mathrm{~N}-\mathrm{C} / \mathrm{C}$, rotating ring-disk electrode (RRDE) measurement was performed to monitor the peroxide species formation during the ORR process (Fig. 4a). Fig. $4 \mathrm{~b}$ indicates that he measured $\mathrm{H}_{2} \mathrm{O}_{2}$ yield is about $5 \%$ over the potential range of $0.2-0.85 \mathrm{~V}$, corresponding to an electron transfer number of $\sim 3.9$ (using the equation (4) and (5) in the experimental section). This is consistent with the result obtained from the RDE measurement, indicating that the ORR catalyzed on $\mathrm{Co} @ \mathrm{CoO} @ \mathrm{~N}-\mathrm{C} / \mathrm{C}$ was mainly through the four electron pathway. In addition, the Co@CoO@N-C/C electrode exhibits superior methanol tolerance ability and durability for ORR relative to $\mathrm{Pt} / \mathrm{C}$. As shown in Fig. 4c and Fig. S14, 15, the ORR polarization curve, $\mathrm{CV}$ curves and i-t chronoamperometric on Co@CoO@N-C/C electrode remained almost unchanged upon the addition of $1 \mathrm{M}$ methanol in the solution. As shown in Fig. $\mathrm{S} 14(\mathrm{a})$, the $\mathrm{CV}$ curve of $\mathrm{Pt} / \mathrm{C}$ electrode in the presence of $1 \mathrm{M}$ methanol showed a typical methanol oxidation peak, indicating that methanol interfere with the ORR process. On the contrary, Co@CoO@N-C/C (Fig. S14b) exhibited a consistent CV curve when methanol was added into the electrolyte. And the i-t chronoamperometric response in Fig. S15 shows that Co@CoO@N$\mathrm{C} / \mathrm{C}$ exhibits a negligible current decrease in $400 \mathrm{~s}$ with the methanol 
addition, however, on $\mathrm{Pt} / \mathrm{C}$ electrode, the current was obviously decayed under the same condition. Both of the above results indicate that $\mathrm{Co} @ \mathrm{CoO} @ \mathrm{~N}-\mathrm{C} / \mathrm{C}$ possesses superior methanol tolerance than $\mathrm{Pt} / \mathrm{C}$. The durability of the materials was evaluated by using a chronoamperometric method at $0.7 \mathrm{~V}$ (Fig. 4d). On the Co@CoO@N-C/C electrode, the relative current exhibited a stable value of $98 \%$ after 20000 s. In contrast, $\mathrm{Co} / \mathrm{CoO} / \mathrm{C}$ and $\mathrm{Pt} / \mathrm{C}$ show a gradual decay with a current loss of approximately $40 \%$ and $37 \%$, respectively. The long-term durability of Co@CoO@N-C/C indicated that the current still persists even subjected to $48 \mathrm{~h}$ testing (Fig. S16, Supporting Information). The morphology of $\mathrm{Co} @ \mathrm{CoO} @ \mathrm{~N}-\mathrm{C} / \mathrm{C}$ remains unchanged after durability measurements (Fig. S17, Supporting Information) The results strongly confirm that Co@CoO@N-C/C is highly stable in the alkaline solution, because the metal is encapsulated by the carbon shell which prevents the electrolyte corrosion directly.
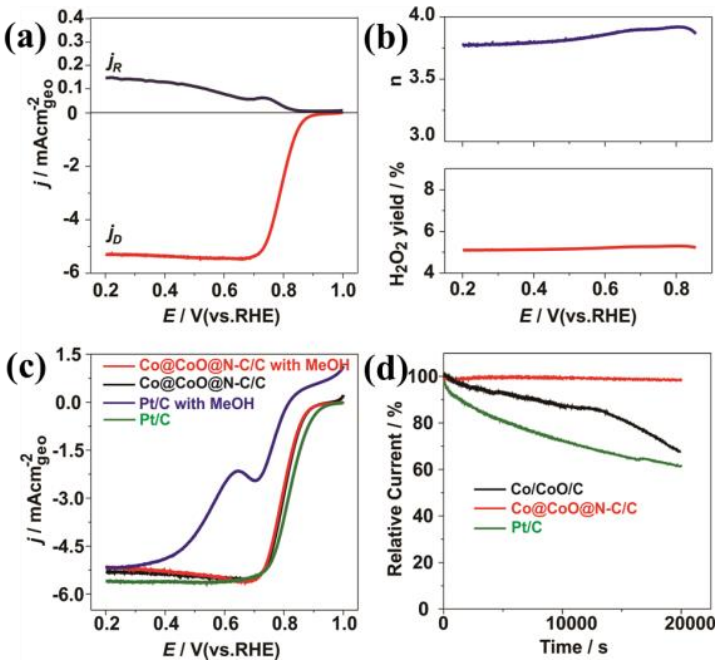

Fig. 4 (a) RRDE voltammograms of $\mathrm{Co} @ \mathrm{CoO} @ \mathrm{~N}-\mathrm{C}$ at a rotating speed of $1600 \mathrm{rpm}$ in $\mathrm{O}_{2}$ saturated $0.1 \mathrm{M} \mathrm{KOH}$ solution. (b) The electron transfer number and peroxide yield obtained from RRDE curves for the Co@CoO@N-C/C. (c) LSVs of $\mathrm{CoCoO} @ \mathrm{~N}-\mathrm{C} / \mathrm{C}$ and Pt-C in $\mathrm{O}_{2}$-saturated $0.1 \mathrm{M} \mathrm{KOH}$ solution in the present of $1 \mathrm{M}$ methanol at a rotation rate of $1600 \mathrm{rpm}$. (d) Current-time (i-t) chronoamperpmetric response of $\mathrm{Co} @ \mathrm{CoO} @ \mathrm{~N}-\mathrm{C} / \mathrm{C}, \mathrm{Co} / \mathrm{CoO} / \mathrm{C}$ and $\mathrm{Pt} / \mathrm{C}$ electrode at $0.7 \mathrm{~V}$ in $\mathrm{O}_{2}$-saturated $0.1 \mathrm{M} \mathrm{KOH}$ solution at a rotation rate of $1600 \mathrm{rpm}$.

\section{Conclusions}

In summary, we have developed a supramolecular gel-assisted method for the synthesis of $\mathrm{N}$-doped carbon shell coated $\mathrm{Co} @ \mathrm{CoO}$ nanoparticles supported on Vulcan XC-72 as nonprecious metal electrocatalysts for the ORR. It is notable that $\mathrm{N}$-doped shell plays a synergistic effect with $\mathrm{Co} @ \mathrm{CoO}$ for the enhanced electrochemical activity for ORR and durability than that of $\mathrm{Co} / \mathrm{CoO} / \mathrm{C}$. In addition, the $\mathrm{Co} @ \mathrm{CoO} @ \mathrm{~N}-\mathrm{C} / \mathrm{C}$ exhibits comparable electrocatalytic activity for ORR relative to commercial $\mathrm{Pt} / \mathrm{C}$ and superior long-term stability and methanol tolerance performance. This research opens up a new strategy for large-scale production of non-precious electrocatalyst for fuel cells application.

\section{Acknowledgements}

This work was supported by the National Natural Science Foundation of China $(21306060,21573083)$, the Program for New Century Excellent Talents in Universities of China (NCET 130237), the Fundamental Research Funds for the Central
University (2013TS136, 2014YQ009). We thank Analytical and Testing Center of Huazhong University of Science \& Technology for allowing us to use its facilities. This research carried out in part at the Center for Functional Nanomaterials, Brookhaven National Laboratory, which is supported by the U.S. Department of Energy, Office of Basic Energy Sciences, under Contract No.DE-SC0012704.

\section{Notes and references}

1. P. G. Bruce, S. A. Freunberger, L. J. Hardwick and J. M. Tarascon, Nat. Mater., 2012, 11, 19-29.

2. M. K. Debe, Nature, 2012, 486, 43-51.

3. C.-M. Zhu, A. Gao, Y. Wang and Y. Liu, Chem. Commun., 2014, 50, 13889-13892

4. D. Wang, H. L. Xin, R. Hovden, H. Wang, Y. Yu, D. A. Muller, F. J. DiSalvo and H. D. Abruña, Nat. Mater., 2013, 12, 81-87.

5. L. Chen, X. Cui, L. Zhang, Y. Wang, M. Wang, F. Cui, C. Wei, J. Feng, T. Ge and W. Ren, ChemSusChem, 2015, 8, 623-627.

6. Q. Lai, Q. Gao, Q. Su, Y. Liang, Y. Wang and Z. Yang, Nanoscale, 2015, 7, 14707-14714.

7. J. Wei, Y. Liang, X. Zhang, G. P. Simon, D. Zhao, J. Zhang, S. Jiang and H. Wang, Nanoscale, 2015, 7, 6247-6254.

8. J. Wang, H. L. Xin, J. Zhu, S. Liu, Z. Wu and D. Wang, J. Mater. Chem. A, 2015, 3, 1601-1608.

9. M. Sun, H. Liu, Y. Liu, J. Qu and J. Li, Nanoscale, 2015, 7, 12501269.

10.J. Wang, H. L. Xin and D. Wang, Part. Part. Syst. Char., 2014, 31 , 515-539.

11.Z. Chen, D. Higgins, A. Yu, L. Zhang and J. Zhang, Energy Environ. Sci., 2011, 4, 3167-3193.

12.B. Wang, J. Power Sources, 2005, 152, 1-15.

13. Q. Li, R. Cao, J. Cho and G. Wu, Adv. Energy Mater., 2014, 4, 1301415.

14.R. Jasinski, Nature, 1964, 201, 1212-1213.

15.J. Van Veen, H. Colijn and J. Van Baar, Electrochim. Acta, 1988, 33, 801-804.

16.C. You, S. Liao, H. Li, S. Hou, H. Peng, X. Zeng, F. Liu, R. Zheng, Z. Fu and Y. Li, Carbon, 2014, 69, 294-301.

17.R. Bashyam and P. Zelenay, Nature, 2006, 443, 63-66.

18.X. Wang, J. S. Lee, Q. Zhu, J. Liu, Y. Wang and S. Dai, Chem. Mater., 2010, 22, 2178-2180.

19.C. Hu, L. Wang, Y. Zhao, M. Ye, Q. Chen, Z. Feng and L. Qu, Nanoscale, 2014, 6, 8002-8009.

20.J. Liu, X. Sun, P. Song, Y. Zhang, W. Xing and W. Xu, $A d v$ Mater., 2013, 25, 6879-6883.

21.P. K. Sukul, D. Asthana, P. Mukhopadhyay, D. Summa, L. Muccioli, C. Zannoni, D. Beljonne, A. E. Rowan and S. Malik, Chem. Commun., 2011, 47, 11858-11860.

22.S.-A. Wohlgemuth, R. J. White, M.-G. Willinger, M.-M. Titirici and M. Antonietti, Green Chem., 2012, 14, 1515-1523.

23.H. Jin, H. Zhang, H. Zhong and J. Zhang, Energy Environ. Sci., 2011, 4, 3389-3394.

24.M. Seredych, J.-C. Idrobo and T. J. Bandosz, J. Mater. Chem. A 2013, 1, 7059-7067.

25.J. S. Shen, Q. G. Cai, Y. B. Jiang and H. W. Zhang, Chem. Commun., 2010, 46, 6786-6788.

26.Z. Lin, M. K. Song, Y. Ding, Y. Liu, M. Liu and C. P. Wong, Phys. Chem. Chem. Phys., 2012, 14, 3381-3387.

27.A. Kong, Y. Kong, X. Zhu, Z. Han and Y. Shan, Carbon, 2014, 78, 49-59.

28.J. Zhang, X.-D. Xu, L.-J. Chen, Q. Luo, N.-W. Wu, D.-X. Wang, X.-L. Zhao and H.-B. Yang, Organometallics, 2011, 30, 40324038. 
29.Q. Yang, X. Tan, S. Wang, J. Zhang, L. Chen, J.-P. Zhang and C.Y. Su, Micropor. Mesopor. Mater., 2014, 187, 108-113.

30.K. Liu, L. Meng, S. Mo, M. Zhang, Y. Mao, X. Cao, C. Huang and T. Yi, J. Mater. Chem. C, 2013, 1, 1753-1762.

31.D. Deng, L. Yu, X. Chen, G. Wang, L. Jin, X. Pan, J. Deng, G. Sun and X. Bao, Angew. Chem. Int. Ed., 2013, 52, 371-375.

32.J. Wang, D. Gao, G. Wang, S. Miao, H. Wu, J. Li and X. Bao, J. Mater. Chem. A, 2014, 2, 20067-20074.

33.J. Deng, P. Ren, D. Deng and X. Bao, Angew. Chem. Int. Ed., 2015, 52, 371-375.

34.Y. Hu, J. O. Jensen, W. Zhang, L. N. Cleemann, W. Xing, N. J. Bjerrum and Q. Li, Angew. Chem., 2014, 53, 3675-3679.

35.H. Li and H. Zhou, Chem. Commun., 2012, 48, 1201-1217.

36.J. Seo, J. W. Chung, I. Cho and S. Y. Park, Soft Matter, 2012, 8, 7617-7622.

37.J. G. Hardy, X.-y. Cao, J. Harrowfield and J.-M. Lehn, New J. Chem., 2012, 36, 668-673.

38. Y. Liang, Y. Li, H. Wang, J. Zhou, J. Wang, T. Regier and H. Dai, Nat. Mater., 2011, 10, 780-786.

39.Y. Meng, D. Voiry, A. Goswami, X. Zou, X. Huang, M. Chhowalla, Z. Liu and T. Asefa, J. Am. Chem. Soc., 2014, 136, 13554-13557.

40.L. Zhang, Z. Su, F. Jiang, L. Yang, J. Qian, Y. Zhou, W. Li and M. Hong, Nanoscale, 2014, 6, 6590-6602.

41.S. Mao, Z. Wen, T. Huang, Y. Hou and J. Chen, Energy Environ. Sci., 2014, 7, 609-616.

42.B. You, P. Yin and L. An, Small, 2014, 21, 4352-4361.

43.S. J. Guo, S. Zhang, L. H. Wu and S. H. Sun, Angew. Chem. Int. Ed., 2012, 51, 11770-11773.

44.D. K. Huang, Y. P. Luo, S. H. Li, B. Y. Zhang, Y. Shen and M. K. Wang, Nano Res., 2014, 7, 1054-1064.

45.R. Bashyam and P. Zelenay, Nature, 2006, 443, 63-66.

46.T. Okada, M. Gokita, M. Yuasa and I. Sekine, J. Electrochem. Soc., 1998, 145, 815-822.

47.G. Nam, J. Park, S. T. Kim, D. B. Shin, N. Park, Y. Kim, J. S. Lee and J. Cho, Nano. Lett., 2014, 14, 1870-1876.

48.S. Liu, C. Deng, L. Yao, H. Zhong and H. Zhang, Int. J. Hydrogen Energy, 2014, 39, 12613-12619.

49.G. Ma, R. Jia, J. Zhao, Z. Wang, C. Song, S. Jia and Z. Zhu, J. Phys. Chem. C, 2011, 115, 25148-25154.

50.S. S. Li, H. P. Cong, P. Wang and S. H. Yu, Nanoscale, 2014, 6, 7534-7541. 